\title{
Class III $\beta$-tubulin is a predictive marker for taxane-based chemotherapy in recurrent and metastatic gastric cancer
}

\author{
Jun-Eul Hwang ${ }^{1}$, Ji-Yun Hong ${ }^{1}$, Karham Kim¹, Seung-Hun Kim', Won-Young Choi ${ }^{1}$, Min-Jee Kim',

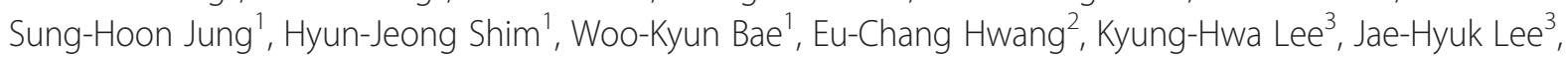 \\ Sang-Hee Cho ${ }^{1}$ and Ik-Joo Chung ${ }^{1 *}$
}

\begin{abstract}
Background: Class III $\beta$-tubulin (TUBB3) is a prognostic marker in various tumors, but the role of TUBB3 in advanced gastric cancer is not clearly defined. We analyzed the significance of TUBB3 expression, along with that of excision repair cross-complementation group 1 (ERCC1) in recurrent and metastatic gastric cancer patients receiving taxane-based first-line palliative chemotherapy.

Methods: We reviewed the cases of 146 patients with advanced gastric adenocarcinoma who received taxane-based first-line palliative chemotherapy between 2004 and 2010 at Chonnam National University Hwasun Hospital (Gwangju, Korea). Immunohistochemical staining for TUBB3 and ERCC1 was performed using paraffin wax-embedded tumor tissues. We evaluated the patients' response to chemotherapy, progression-free survival (PFS), and overall survival (OS).

Results: In total, 146 patients with advanced gastric cancer received docetaxel and cisplatin $(n=15)$ or paclitaxel and cisplatin $(n=131)$. The median PFS was significantly shorter for patients with high-level TUBB3 expression than for patients with low-level TUBB3 expression (3.63 vs. 6.67 months, $P=0.001$ ). OS was not associated with TUBB3 expression (13.1 vs. 13.1 months, $P=0.769$ ). By multivariate analysis, only TUBB3 was related to a shorter PFS (HR 2.74, 95\% Cl 1.91-3.91, $P=0.001$ ). Patients with high-level ERCC1 expression showed a lower response rate than patients with low-level ERCC1 expression (24 vs. 63.2\%, $P=0.001$ ); however, ERCC1 had no clinical effect on PFS or OS.
\end{abstract}

Conclusions: TUBB3 was a strong predictive marker in recurrent and metastatic gastric cancer patients receiving taxane-based first-line palliative chemotherapy. No clinical impact of ERCC1 was evident in this setting.

Keywords: Class III $\beta$-tubulin (TUBB3), Excision repair cross-complementation group 1 (ERCC1), Taxane, Stomach neoplasm, Metastasis

\section{Background}

Gastric cancer is one of the leading causes of cancer-related death. Although its global incidence is declining, gastric cancer remains highly prevalent in many Asian countries $[1,2]$. Conventional treatments such as surgery, radiotherapy, and chemotherapy play a role primarily in patients with early-stage disease. However, they have only modest efficacy in treating patients with recurrent or metastatic gastric cancer [3].

\footnotetext{
* Correspondence: ijchung@chonnam.ac.kr

'Department of Hematology-Oncology, Chonnam National University Hwasun Hospital, 322 Seoyang-ro, Hwasun-eup, Hwasun-gun, Jeonnam 519-763, Korea

Full list of author information is available at the end of the article
}

Molecular and genetic alterations are complex in the pathogenesis of gastric cancer. Many different cellular pathways may play important roles in gastric carcinogenesis, and the predominant driving pathway can be difficult to delineate $[4,5]$. However, recently, HER-2 overexpression and amplification were shown to be effective predictive markers in gastric cancer with the release of promising results from the Trastuzumab for Gastric Cancer trial [6]. Predictive biomarkers indicate the likely benefit of treatment, whereas prognostic biomarkers are associated with survival that is independent of the treatment effect. Markers can be prognostic and/or predictive [7].

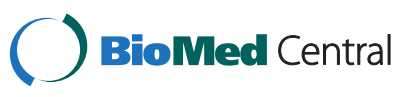


Taxanes (docetaxel and paclitaxel) are anticancer agents that bind to microtubules and induce hyperstabilization, causing a cell cycle arrest and apoptosis [8,9]. They are widely used and effective chemotherapeutic agents in advanced gastric cancer [10-16]. Class III $\beta$-tubulin (TUBB3) has been shown to play a role in chemotherapy resistance in various cancer types [17]. The role of TUBB3 has been studied in non-small cell lung cancer (NSCLC), and it has been shown to be associated with resistance to antitubulin agents, including taxanes $[18,19]$. TUBB3 is also a prognostic factor in NSCLC. However, the role of TUBB3 in gastric cancer has not been widely investigated, although it is important in the treatment of gastric cancer to predict chemosensitivity with the goal of improving the response rate and overall survival (OS), and preventing unnecessary side effects and useless treatments. Thus, TUBB3 may provide important information for planning gastric cancer treatment regimens.

Excision repair cross-complementation group 1 (ERCC1) has also been investigated in NSCLC. It is a prognostic marker for resected NSCLC and a predictor of a lack of benefit from platinum-based adjuvant chemotherapy [20,21]. The role of ERCC1 in advanced gastric cancer has not been extensively evaluated. There is a report suggesting that high levels of ERCC1 expression in gastric cancer may be associated with poor survival and a lack of response to cisplatin [22]; however, its role remains controversial.

In this study, we analyzed the significance of TUBB3 and ERCC1 in recurrent and metastatic gastric cancer patients receiving first-line palliative chemotherapy. The chemotherapeutic regimens used consisted of taxane (paclitaxel or docetaxel) and cisplatin. The objective of this study was to determine the role of TUBB3 and ERCC1 as predictive or prognostic markers in taxane + cisplatin chemotherapy.

\section{Methods \\ Patients}

We reviewed the cases of 146 patients with unresectable recurrent or metastatic gastric adenocarcinoma who were treated with taxane-based first-line palliative chemotherapy between January 2004 and December 2010 at Chonnam National University Hwasun Hospital (Gwangju, Korea), and whose paraffin wax-embedded tumor tissue at diagnosis and medical records were available (Figure 1). We used endoscopic biopsy specimens in cases of initially metastatic patients, whereas resected samples were used in cases of recurrence after curative resection. Patients were staged using a combination of endoscopy, computed tomographic scans of the chest and abdomen, and positron emission tomography or bone scans, when clinically indicated. Data regarding patient demographics, chemotherapeutic regimen, chemotherapy response, progression-free survival (PFS), and OS were obtained by medical record review.

\section{Chemotherapy}

The chemotherapy regimens consisted of cycles of taxane (paclitaxel or docetaxel) and cisplatin. In total, 131 patients received PC chemotherapy, consisting of paclitaxel (175 mg/m ${ }^{2}$ of Taxol; Bristol-Myers Squibb Pharmaceuticals, New York, NY, USA) and cisplatin $\left(75 \mathrm{mg} / \mathrm{m}^{2}\right)$ on day 1 , while 15 patients received DC chemotherapy, consisting of docetaxel $\left(75 \mathrm{mg} / \mathrm{m}^{2}\right.$ of Taxotere; Sanofi Aventis, Paris, France) and cisplatin $\left(75 \mathrm{mg} / \mathrm{m}^{2}\right)$ on day 1 . Each regimen was repeated every 3 weeks.

The schedule was repeated until the occurrence of disease progression, lack of clinical benefit, unacceptable toxicity, or patient refusal. Hematological and non-hematological adverse events were evaluated. The management of adverse events and subsequent dose reduction of chemotherapeutic agents was carried out in a conventional manner. A total of 92 patients received full-dose intense chemotherapy, while 54 patients required a modification of the dose or chemotherapy interval.

\section{Response evaluation}

The clinical tumor response was assessed radiologically by computed tomography after every two courses of chemotherapy, according to the Response Evaluation Criteria in Solid Tumors (ver. 1.0) [23]. PFS was defined as the period from the start of chemotherapy to documentation of disease progression or death from any cause, whichever occurred first. If neither event had occurred at the time of the last record, the patient was censored at that time. OS was calculated from the start of chemotherapy to death from any cause.

This study protocol was reviewed and approved by the Institutional Review Board of Chonnam National University Medical School Research Institution. Written informed consent was obtained from all patients prior to their inclusion in the study.

\section{Immunohistochemical staining for TUBB3 and ERCC1}

Immunohistochemical staining for TUBB3 and ERCC1 was performed on paraffin wax-embedded tissue sections. The sections $(4 \mu \mathrm{m})$ were deparaffinized, rehydrated, rinsed with distilled water, and washed with Tris-buffered saline. Antigen retrieval was performed using a heatinduced epitope retrieval method. Avidin-biotin peroxidase complexes were identified using diaminobenzidine (Sigma-Aldrich, St. Louis, MO, USA) as the chromogen with a streptavidin-horseradish peroxidase detection system (Ventana; Biotek Solutions, Tucson, AZ, USA). A rabbit monoclonal antibody against TUBB3 (clone EP1331Y, 1:250; Abcam PLC, Cambridge, UK) and a mouse monoclonal antibody against ERCC1 (clone 8 F1, 1:100; Abcam PLC) were used as primary antibodies. Antibody use and all subsequent steps were performed 


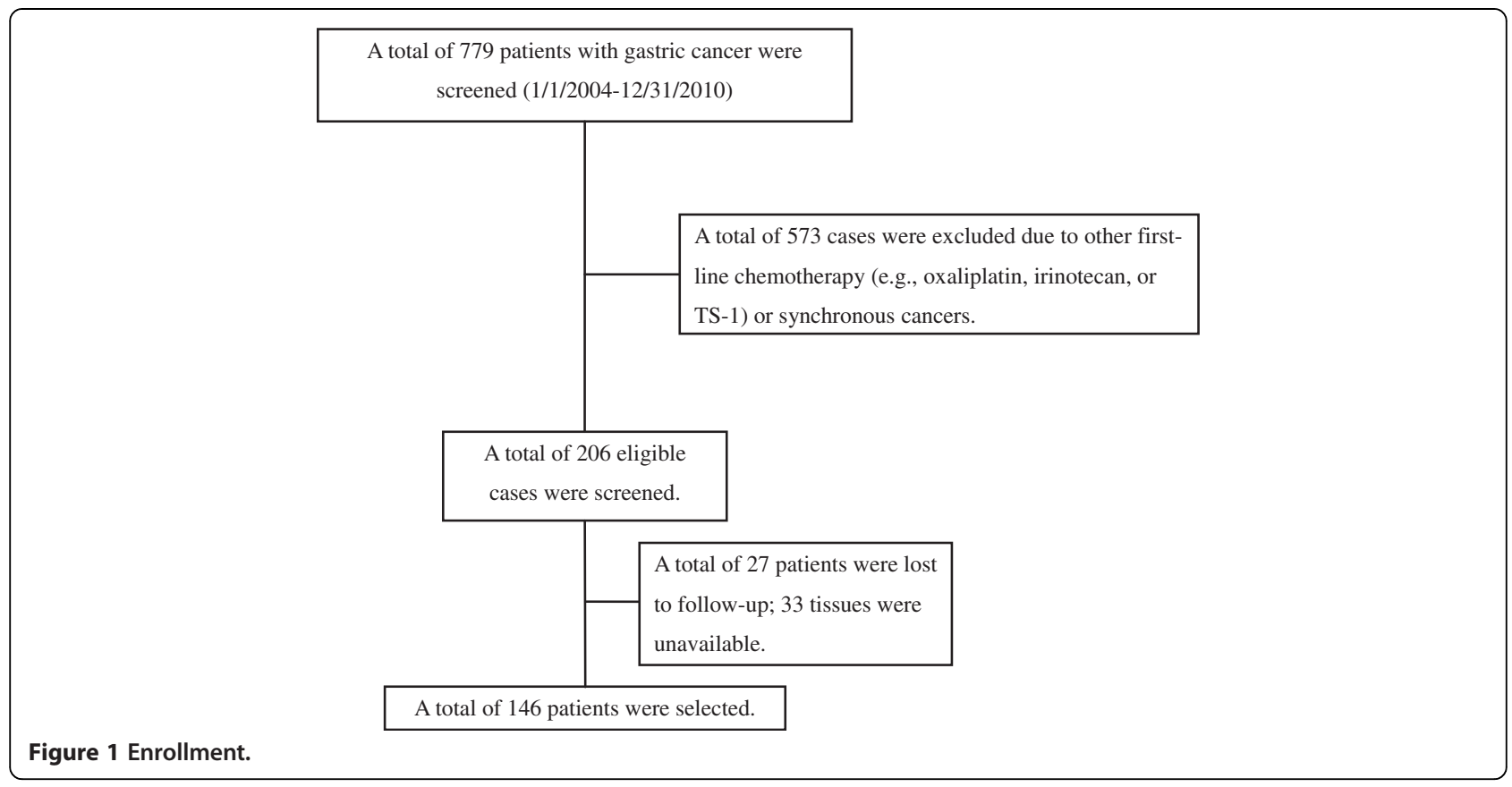

according to the manufacturer's instructions. Immunohistochemical staining was repeated for samples giving inconsistent results. H-scores $\geq 4$ (median value for both TUBB3 and ERCC1) for TUBB3 and ERCC1 were classified as high-level expression.

\section{Microscopic analysis}

All of the immunostaining results were assessed by two independent pathologists (JHL and KHL) who had no knowledge of the patients' clinical data. The TUBB3 and ERCC1 staining intensities (cytoplasmic staining for TUBB3 and nuclear staining for ERCC1) were graded on a scale of 0 to $2(0=$ none, $1=$ weak, and $2=$ strong $)$, using adjacent non-malignant cells for reference. The percentage of positive tumor cells was evaluated and a proportion score was attributed to TUBB3 and ERCC1 ( 0 if $0 \%, 1$ if $1-10 \%, 2$ if $11-50 \%$, and 3 if $51-100 \%$ ). This proportion score was multiplied by the staining intensity to obtain a final semi-quantitative $\mathrm{H}$-score for TUBB3 and ERCC1 [24].

\section{Statistical analysis}

Variables for inclusion in the model were age, sex, tumor location, histological grade, Lauren's classification, disease status, liver metastasis, bone metastasis, peritoneal metastasis, chemotherapy response, chemotherapeutic regimen, number of involved organs, TUBB3 expression, and ERCC1 expression. A comparison of clinicopathological parameters was evaluated with Pearson's chi-squared test or Fisher's exact test, as appropriate. Odds ratios (ORs) with confidence intervals (CIs) for categorical outcomes were calculated using a binary logistic regression model. The
Kaplan-Meier method was used to construct PFS curves. Differences between survival curves were tested using the log-rank test. To identify independent factors significantly related to patient prognosis, we used Cox proportional hazard analysis with a step-wise forward procedure.

All statistical tests were two sided, and $P<0.05$ were considered to indicate statistical significance. All analyses were performed using SPSS software (ver. 17.0; SPSS, Inc., Chicago, IL, USA).

\section{Results}

\section{Patient characteristics}

The demographic details of the patients are presented in Table 1. In total, 146 patients received taxane-based first-line palliative chemotherapy. The median age of the patients was 56 (range, 19-75) years; the study population included 104 males (71.2\%) and 42 females (28.8\%). Regarding the histopathological classification, 86 (59.0\%) were intestinal, 43 (29.4\%) were diffuse, and 17 (11.6\%) were mixed-type. In total, 90 patients $(61.6 \%)$ had initially metastatic disease, and 56 patients (38.4\%) had recurrent disease after curative resections. In total, 766 treatment cycles were delivered, with a median number of five cycles per patient (range, 1-15). A total of 9 patients (6.2\%) received more than ten cycles of chemotherapy.

\section{TUBB3 and ERCC1 expression}

Of the 146 archival specimens, 77 (52.7\%) and 78 (53.4\%) showed high-level expression of TUBB3 and ERCC1, respectively. The immunostaining patterns for TUBB3 were cytoplasmic, whereas the ERCC1 expression patterns in the tumor cells were nuclear (Figure 2) The expression 
Table 1 Patient characteristics

$\begin{array}{cc}\begin{array}{c}\text { Low-level TUBB3 } \\ \text { expression } \\ \text { H-score 1-3 }\end{array} & \begin{array}{c}\text { High-level TUBB3 } \\ \text { expression }\end{array}\end{array} \quad P$

\begin{tabular}{llll}
\hline Age & & & \\
$<56$ & $32(44.4)$ & $40(55.6)$ & 0.105 \\
$\geq 56$ & $37(50.0)$ & $37(50.0)$ & \\
Sex & & & \\
$\quad$ Male & $49(47.1)$ & $55(52.9)$ & 1 \\
Female & $20(47.6)$ & $22(52.4)$ & \\
Location & & & \\
GEJ-cardia & $9(56.3)$ & $7(43.8)$ & 0.8 \\
Body & $42(45.7)$ & $50(54.3)$ & \\
Antrum & $18(47.4)$ & $20(52.6)$ & \\
Differentiation & & & \\
Well, moderately & $15(41.7)$ & $21(58.3)$ & 0.45 \\
Poorly, signet ring cell & $54(49.1)$ & $56(509)$ &
\end{tabular}

Lauren classification

Intestinal

$41(47.7)$

Diffuse

Mixed

Disease status

Initial metastasis

Recurrence after

curative resection

Metastatic site

Liver

Yes

No

Peritoneum

Yes

No

Bone

Yes

No

Chemotherapy response

$$
C R+P R
$$

$\mathrm{SD}+\mathrm{PD}$

Chemotherapeutic regimen

Paclitaxel and
cisplatin

Docetaxel and cisplatin

No. of involved organs

$$
1
$$$$
2
$$$$
\geq 3
$$

$41(45.6) \quad 49(54.4) \quad 0.614$

$28(50.0) \quad 28(50.0)$

$\begin{array}{ll}41(41.8) & 57(58.2) \\ 25(61.0) & 16(39.0) \\ 3(42.9) & 4(57.1)\end{array}$

Table 1 Patient characteristics (Continued)

\begin{tabular}{cccc}
\hline ERCC1 H-score & & & \\
$1-3$ & $36(52.9)$ & $32(47.1)$ & 0.245 \\
$4-6$ & $33(42.3)$ & $45(57.7)$ & \\
\hline
\end{tabular}

$G E J$, gastrointestinal junction; $C R$, complete response; $P R$, partial response; $S D$, stable disease; $P D$, progressive disease; TUBB3, class III $\beta$-tubulin; ERCC1, excision repair cross-complementation group 1.

status of TUBB3 and ERCC1 did not correlate with each other $(P=0.245)$.

\section{Correlations between the expression of TUBB3 and ERCC1} and clinicopathological parameters

No clinical parameter examined was associated with TUBB3 expression. ERCC1 expression was only associated with response rate. The response rate $(\mathrm{CR}+\mathrm{PR})$ to chemotherapy was $44 \%$. Patients with high-level ERCC1 expression showed significantly lower response rates than patients with low-level ERCC1 expression (24.4 vs. 63.2\%, $P=0.001)$. High-level TUBB3 expression was associated with a lower response rate, but not significantly so (36.4 vs. 49.3\%, $P=0.115$ ). By multivariate analysis, considering chemotherapy response, ERCC1 was a negative predictive marker for response rate (adjusted OR 5.038, 95\% CI 2.44$10.37, P=0.001)$.

\section{Expression of TUBB3 and ERCC1 and clinical outcome}

The median follow-up duration (from the first visit to death or the date of last follow-up) was 23.7 months (range, 4.9-75.4 months). Six patients were alive at the time of analysis. The median PFS and OS of the patients were 4.4 months (95\% CI 3.74-5.11) and 13.1 months (95\% CI 10.5-15.6), respectively. Univariate analyses of the clinicopathological parameters and PFS and OS are shown in Table 2. In the univariate analysis, high-level TUBB3 expression was significantly associated with a shorter PFS (median 3.6 vs. 6.7 months; $P=0.001$; Table 2 and Figure 3). OS was not associated with TUBB3 expression status (13.1 vs. 13.1 months; $P=0.769)$. ERCC1 showed no clinical effect on PFS or OS. PFS was 3.8 months in the high-level ERCC1 expression group and 5.2 months in the low-level expression group $(P=0.28)$. OS was in 12.7 months in the high-level ERCC1 expression group and 13.5 months in the low-level expression group $(P=0.916)$. In the multivariate analysis, high-level TUBB3 expression was an independent prognostic factor for poor PFS (HR 2.74, 95\% CI 1.91-3.91, $P=0.001)$. No clinical parameter examined was significantly associated with PFS or OS. Neither TUBB3 nor ERCC1 predicted OS.

\section{Discussion}

Tubulin-binding agents are an important class of compounds in the field of anti-neoplastic chemotherapy, with broad activity in both solid tumors and hematological 


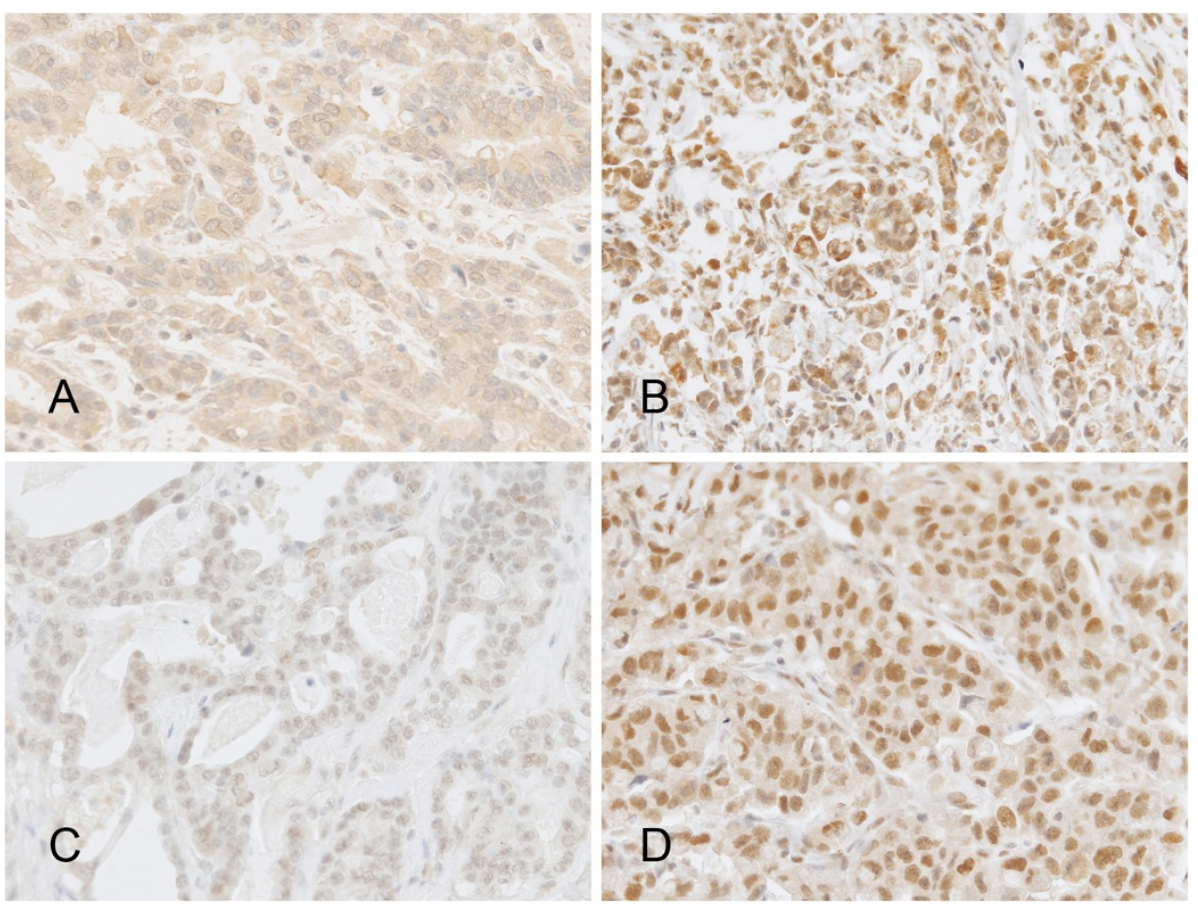

Figure 2 Representative examples of class III $\beta$-tubulin (TUBB3) and excision repair cross-complementation group 1 (ERCC1) immunostaining (×200). (A) TUBB3 H-score < 4. (B) TUBB3 H-score =6. (C) ERCC1 H-score < 4. (D) ERCC1 H-score $=6$.

malignancies [14,25]. These agents block cell division by inhibiting the mitotic spindle. Taxanes (paclitaxel and docetaxel) promote the polymerization of purified tubulin in vitro at high concentrations and enhance the fraction of polymerized tubulin in cells. Thus, they have been referred to as microtubule-stabilizing agents.

Several mechanisms have been reported to be involved in resistance to tubulin-binding agents. One is TUBB3 overexpression. Many preclinical studies have shown that high levels of TUBB3 expression are associated with taxane resistance in various human cancer cell lines, including lung, ovary, prostate, breast, and pancreas [26-29].

In NSCLC, TUBB3 is considered to be a predictive marker for chemotherapy and a prognostic marker at the same time. That is, high-level expression of TUBB3 is associated with a poorer response to chemotherapy, faster disease progression, and worse survival in NSCLC patients $[18,19,30]$. Several clinical studies have assessed the prognostic or predictive value of TUBB3 expression in patients with ovarian, cervical, or breast cancer. Most of these studies have shown that TUBB3 expression is associated with resistance to tubulin binding agents, a poor prognosis, or both [17]. Koh et al. [31] also reported that TUBB3-positive patients showed lower response rates, and that the PFS and OS times were shorter in patients with head and neck squamous cell carcinoma receiving induction chemotherapy.
Taxanes are widely used in gastric cancer, and the identification of predictive markers for specific drugs would be of value in tailoring therapy to the specific profile of individual patients and tumors. A small cohort study of advanced gastric cancer patients who were receiving preoperative docetaxel-based chemotherapy showed a correlation between TUBB3 expression and a poor response to chemotherapy [32]. Lu et al. [33] analyzed TUBB3 mRNA expression (as determined by realtime quantitative polymerase chain reaction) in patients with advanced gastric cancer receiving first-line paclitaxel plus capecitabine chemotherapy. They demonstrated that high-level TUBB3 expression was significantly associated with a lower response rate and shorter PFS and OS.

In this study, high-level expression of TUBB3 was associated with a shorter PFS and a tendency to have a reduced response to chemotherapy, but was not associated with OS in recurrent or metastatic gastric cancer patients receiving taxane-based first-line palliative chemotherapy.

OS was affected by many clinical factors, including performance status, second-line chemotherapy, and comorbidities, in patients with advanced gastric cancer receiving palliative chemotherapy [34]. OS may have been affected by the same clinical factors in this study.

ERCC1 is currently under investigation in gastric cancer, but the influence of ERCC1 expression remains controversial. Several recent reports demonstrated that high-level expression of ERCC1 was correlated with platinum resistance 
Table 2 Univariate analysis of PFS and OS

\begin{tabular}{|c|c|c|c|c|}
\hline & $\begin{array}{l}\text { mPFS } \\
(95 \% \mathrm{Cl})\end{array}$ & $P$ & $\begin{array}{l}\text { mOS } \\
(95 \% \mathrm{Cl})\end{array}$ & $P$ \\
\hline \multicolumn{5}{|l|}{ Age } \\
\hline$<56$ & $4.07(3.27-4.87)$ & 0.937 & $12.73(9.46-15.99)$ & 0.453 \\
\hline$\geq 56$ & $4.70(3.35-6.04)$ & & $13.10(10.10-16.09)$ & \\
\hline \multicolumn{5}{|l|}{ Sex } \\
\hline Male & $4.27(3.49-5.04)$ & 0.915 & $12.10(10.43-13.76)$ & 0.072 \\
\hline Female & $4.43(2.02-6.83)$ & & $15.37(11.48-19.25)$ & \\
\hline \multicolumn{5}{|l|}{ Location } \\
\hline GEJ-cardia & $3.83(1.16-6.49)$ & 0.926 & $14.03(4.50-23.55)$ & 0.903 \\
\hline Body & $4.7(3.95-5.44)$ & & $12.37(9.17-15.56)$ & \\
\hline Antrum & $3.93(0.47-4.38)$ & & $14.17(11.14-17.19)$ & \\
\hline \multicolumn{5}{|l|}{ Differentiation } \\
\hline $\begin{array}{l}\text { Well, moderately } \\
\text { differentiated }\end{array}$ & $3.83(3.49-4.16)$ & 0.530 & $12.10(7.79-16.40)$ & 0.200 \\
\hline $\begin{array}{l}\text { Poorly, signet ring } \\
\text { cell type }\end{array}$ & $4.67(3.77-5.56)$ & & 13.13 (10.19-16.06) & \\
\hline \multicolumn{5}{|l|}{ Lauren classification } \\
\hline Intestinal & $4.20(3.29-5.10)$ & 0.479 & $13.10(9.95-16.24)$ & 0.626 \\
\hline Diffuse & $4.27(2.85-5.68)$ & & $13.13(9.62-16.63)$ & \\
\hline Mixed & $4.93(2.20-7.65)$ & & $11.70(2.55-20.84)$ & \\
\hline \multicolumn{5}{|l|}{ Disease status } \\
\hline $\begin{array}{l}\text { Recurrence after } \\
\text { curative resection }\end{array}$ & $4.20(3.13-5.26)$ & 0.714 & $12.10(9.69-14.50)$ & 0.962 \\
\hline Initial metastasis & $4.43(3.36-5.49)$ & & $14.17(11.10-17.23)$ & \\
\hline \multicolumn{5}{|l|}{ Liver metastasis } \\
\hline Yes & $4.70(2.89-6.50)$ & 0.537 & $14.03(9.13-18.9)$ & 0.586 \\
\hline No & $4.27(3.49-5.04)$ & & $13.10(10.06-16.14)$ & \\
\hline
\end{tabular}

Bone metastasis

Yes

No

Peritoneal metastasis

Yes

No

Chemotherapy

response

$C R, P R$

$\mathrm{SD}, \mathrm{PD}$

Chemotherapeutic regimen

$\begin{array}{lllll}\text { Paclitaxel/cisplatin } & 4.07(3.52-4.61) & 0.224 & 12.37(10.23-14.50) & 0.221 \\ \text { Docetaxel/cisplatin } & 6.50(5.71-7.28) & 17.87(14.42-21.31) & \\ \text { No. of involved organs } & & & & \\ 1 & 3.97(3.17-4.76) & 0.220 & 12.10(9.15-15.04) & 0.570 \\ 2 & 4.73(2.76-6.70) & 15.13(10.11-20.14) & \\ \geq 3 & 7.07(0.00-16.05) & 12.40(9.91-14.88) & \end{array}$

Table 2 Univariate analysis of PFS and OS (Continued)

\begin{tabular}{|c|c|c|c|c|}
\hline \multicolumn{5}{|l|}{ TUBB3 } \\
\hline $\begin{array}{l}\text { High-level } \\
\text { expression }\end{array}$ & $3.63(3.37-3.88)$ & 0.001 & $13.13(9.88-16.37)$ & 0.769 \\
\hline $\begin{array}{l}\text { Low-level } \\
\text { expression }\end{array}$ & $6.67(5.65-7.68)$ & & $13.10(8.83-17.36)$ & \\
\hline \multicolumn{5}{|l|}{ ERCC1 } \\
\hline $\begin{array}{l}\text { High-level } \\
\text { expression }\end{array}$ & 3.77 (3.54-3.99) & 0.280 & 12.70 (9.45-15.94) & 0.916 \\
\hline $\begin{array}{l}\text { Low-level } \\
\text { expression }\end{array}$ & $5.23(3.74-6.71)$ & & $13.53(10.10-16.95)$ & \\
\hline
\end{tabular}

and poor recurrence-free survival and OS in gastric cancer $[35,36]$. In contrast, other studies have demonstrated that low-level ERCC1 expression was correlated with poor survival or showed no correlation with survival $[37,38]$. These seemingly conflicting results may be related to biological variation in the tumors analyzed, to variation in the chemotherapeutic protocols, and/or to the different techniques used to assess ERCC1 expression.

In this study, ERCC1 had no effect on PFS or OS, and was only associated with the clinical response to chemotherapy. There is a clinical study showing that paclitaxel may help alleviate ERCC1-related platinum resistance in ovarian cancer [39]. Cisplatin monotherapy is not commonly used; taxane monotherapy is used to treat advanced gastric cancer $[40,41]$. Thus, paclitaxel might play a greater role than cisplatin in patients with advanced gastric cancer treated with taxane-cisplatin chemotherapy.

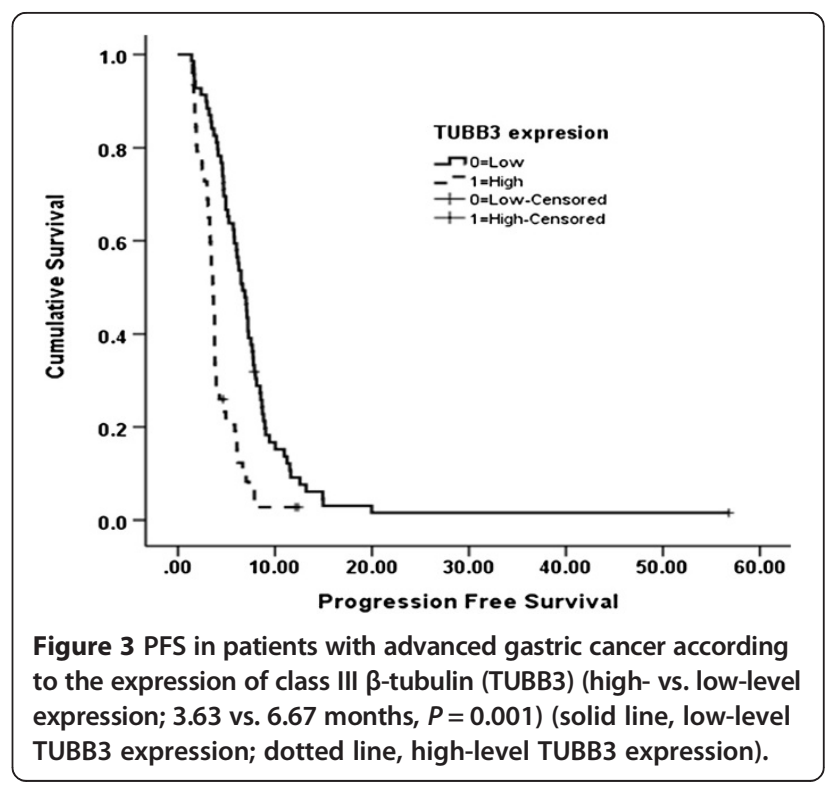


Despite demonstrating the predictive significance of TUBB3 expression, the present study has several potential limitations. First, it was a retrospective analysis from a single institution. Therefore, the chemotherapy dose and schedule might be different from patient to patient according to individual patient organ function, tolerability, and toxicity profiles. Second, this study included a somewhat heterogeneous patient population. Among 146 patients, 90 initially presented with metastatic disease, whereas 56 had recurrent disease after curative resection. Third, TUBB3 expression did not correlate with other clinical parameters such as histological grade or Lauren classification. Finally, it is possible that the immunohistochemical staining results of the pretreatment endoscopic biopsy specimens or resected samples did not correlate with those of the entire primary tumor or metastatic tissue.

Additional prospective, randomized controlled trials are needed to identify the true significance of TUBB3 and ERCC1 in the prognosis of gastric cancer. Randomized clinical trials may also account for confounding variables such as patient performance status.

\section{Conclusions}

In conclusion, in advanced gastric cancer, TUBB3 was a predictive marker for taxane-cisplatin chemotherapy. ERCC1 was not associated with PFS or OS. Immunohistochemical analysis of pre-treatment biopsies for TUBB3 may provide valuable information to oncologists in selecting appropriate chemotherapeutic regimens.

\section{Abbreviations \\ TUBB3: Class III $\beta$-tubulin; ERCC1: Excision repair cross-complementation group 1; PFS: Progression-free survival; OS: Overall survival; NSCLC: Non-small cell lung cancer; OR: Odds ratio; HR: Hazard ratio; Cl: Confidence interval.}

\section{Competing interests}

The authors declare that they have no competing interests.

\section{Authors' contributions}

JEH drafted the manuscript. JYH, KK, SHK, WYC, MJK, and SHJ collected the clinical data. JEH, HJS, WKB, SHC, and IJC performed the chemotherapy and revised the manuscript. ECH made a special contribution to the statistical analysis. $\mathrm{KHL}$ and $\mathrm{JHL}$ analyzed the pathological data. IJC conceived of the study and approved the final manuscript. All authors read and approved the final manuscript.

\section{Acknowledgements}

We thank Ji-Hee Lee and Mi-Ra Park for performing the antibody staining. We also thank Kyung-Hwa Lee and Jae-Hyuk Lee for conducting the pathological data analyses.

The English in this document has been checked by at least two professional editors, both native speakers of English. For a certificate, please see: http://www.textcheck.com/certificate/cWdCSj.

\section{Author details}

'Department of Hematology-Oncology, Chonnam National University Hwasun Hospital, 322 Seoyang-ro, Hwasun-eup, Hwasun-gun, Jeonnam 519-763, Korea. ${ }^{2}$ Department of Urology, Chonnam National University Hwasun Hospital, Jeonnam, Korea. ${ }^{3}$ Department of Pathology, Chonnam National University Hwasun Hospital, Jeonnam, Korea.
Received: 25 April 2013 Accepted: 17 September 2013

Published: 23 September 2013

\section{References}

1. Siegel R, Ward E, Brawley O, Jemal A: Cancer statistics, 2011: the impact of eliminating socioeconomic and racial disparities on premature cancer deaths. CA Cancer J Clin 2011, 61(4):212-236.

2. Kamangar F, Dores GM, Anderson WF: Patterns of cancer incidence, mortality, and prevalence across five continents: defining priorities to reduce cancer disparities in different geographic regions of the world. J Clin Oncol 2006, 24(14):2137-2150

3. Wagner AD, Grothe W, Behl S, Kleber G, Grothey A, Haerting J, Fleig WE: Chemotherapy for advanced gastric cancer. Cochrane Database Syst Rev 2005, 2:CD004064.

4. Wu K, Nie Y, Guo C, Chen Y, Ding J, Fan D: Molecular basis of therapeutic approaches to gastric cancer. J Gastroenterol Hepatol 2009, 24(1):37-41.

5. Yin M, Hu Z, Tan D, Ajani JA, Wei Q: Molecular epidemiology of genetic susceptibility to gastric cancer: focus on single nucleotide polymorphisms in gastric carcinogenesis. Am J Trans/ Res 2009, 1(1):44-54.

6. Bang YJ, Van Cutsem E, Feyereislova A, Chung HC, Shen L, Sawaki A, Lordick F, Ohtsu A, Omuro Y, Satoh T, et al: Trastuzumab in combination with chemotherapy versus chemotherapy alone for treatment of HER2positive advanced gastric or gastro-oesophageal junction cancer (ToGA): a phase 3, open-label, randomised controlled trial. Lancet 2010, 376(9742):9687-9697.

7. Cunningham D, Atkin W, Lenz HJ, Lynch HT, Minsky B, Nordlinger B, Starling N: Colorectal cancer. Lancet 2010, 375(9719):1030-1047.

8. Schiff PB, Fant J, Horwitz SB: Promotion of microtubule assembly in vitro by taxol. Nat 1979, 277(5698):665-667.

9. Ganansia-Leymarie V, Bischoff P, Bergerat JP, Holl V: Signal transduction pathways of taxanes-induced apoptosis. Curr Med Chem Anticancer Agents 2003, 3(4):291-306

10. Murad AM, Petroianu A, Guimaraes RC, Aragao BC, Cabral LO, ScalabriniNeto AO: Phase II trial of the combination of paclitaxel and 5-fluorouracil in the treatment of advanced gastric cancer: a novel, safe, and effective regimen. Am J Clin Oncol 1999, 22(6):580-586.

11. Kim YH, Shin SW, Kim BS, Kim JH, Kim JG, Mok YJ, Kim CS, Rhyu HS, Hyun JH, Kim JS: Paclitaxel, 5-fluorouracil, and cisplatin combination chemotherapy for the treatment of advanced gastric carcinoma. Cancer 1999, 85(2):295-301.

12. Roth $A D$, Maibach R, Martinelli G, Fazio N, Aapro MS, Pagani O, Morant $R$, Borner MM, Herrmann R, Honegger $\mathrm{H}$, et al: Docetaxel (Taxotere)-cisplatin (TC): an effective drug combination in gastric carcinoma. Swiss Group for Clinical Cancer Research (SAKK), and the European Institute of Oncology (EIO). Ann Oncol 2000, 11(3):301-306.

13. Constenla M, Garcia-Arroyo R, Lorenzo I, Carrete N, Campos B, Palacios P: Docetaxel, 5-fluorouracil, and leucovorin as treatment for advanced gastric cancer: results of a phase II study. Gastric Cancer 2002, 5(3):142-147.

14. Ajani JA, Fodor MB, Tjulandin SA, Moiseyenko VM, Chao Y, Cabral Filho S, Majis A, Assadourian S, Van Cutsem E: Phase II multi-institutional randomized trial of docetaxel plus cisplatin with or without fluorouracil in patients with untreated, advanced gastric, or gastroesophageal adenocarcinoma. J Clin Oncol 2005, 23(24):5660-5667.

15. Van Cutsem E, Moiseyenko VM, Tjulandin S, Majlis A, Constenla M, Boni C, Rodrigues $\mathrm{A}$, Fodor M, Chao $\mathrm{Y}$, Voznyi E, et al: Phase III study of docetaxel and cisplatin plus fluorouracil compared with cisplatin and fluorouracil as first-line therapy for advanced gastric cancer: a report of the V325 Study Group. J Clin Oncol 2006, 24(31):4991-4997.

16. Hwang J, Cho SH, Shim HJ, Lee SR, Ahn JS, Yang DH, Kim YK, Lee JJ, Kim HJ, Chung IJ: Phase II study of paclitaxel, cisplatin, and 5-fluorouracil combination chemotherapy in patients with advanced gastric cancer. J Korean Med Sci 2008, 23(4):586-591.

17. Seve $\mathrm{P}$, Dumontet $\mathrm{C}$ : Is class III beta-tubulin a predictive factor in patients receiving tubulin-binding agents? Lancet Oncol 2008, 9(2):168-175.

18. Seve P, Isaac S, Tredan O, Souquet PJ, Pacheco Y, Perol M, Lafanechere L, Penet A, Peiller EL, Dumontet C: Expression of class III \{beta\}-tubulin is predictive of patient outcome in patients with non-small cell lung cancer receiving vinorelbine-based chemotherapy. Clin Cancer Res 2005, 11(15):5481-5486. 
19. Seve P, Mackey J, Isaac S, Tredan O, Souquet PJ, Perol M, Lai R, Voloch A, Dumontet C: Class III beta-tubulin expression in tumor cells predicts response and outcome in patients with non-small cell lung cancer receiving paclitaxel. Mol Cancer Ther 2005, 4(12):2001-2007.

20. Arriagada R, Bergman B, Dunant A, Le Chevalier T, Pignon JP, Vansteenkiste $\mathrm{J}$ : Cisplatin-based adjuvant chemotherapy in patients with completely resected non-small-cell lung cancer. N Engl J Med 2004, 350(4):351-360.

21. Olaussen KA, Dunant A, Fouret P, Brambilla E, Andre F, Haddad V, Taranchon E, Filipits M, Pirker R, Popper HH, et al: DNA repair by ERCC1 in non-small-cell lung cancer and cisplatin-based adjuvant chemotherapy. N Engl J Med 2006, 355(10):983-991.

22. Metzger R, Leichman CG, Danenberg KD, Danenberg PV, Lenz HJ, Hayashi K, Groshen S, Salonga D, Cohen H, Laine L, et al: ERCC1 mRNA levels complement thymidylate synthase mRNA levels in predicting response and survival for gastric cancer patients receiving combination cisplatin and fluorouracil chemotherapy. J Clin Oncol 1998, 16(1):309-316.

23. Therasse P, Arbuck SG, Eisenhauer EA, Wanders J, Kaplan RS, Rubinstein L, Verweij J, Van Glabbeke M, van Oosterom AT, Christian MC, et al: New guidelines to evaluate the response to treatment in solid tumors. European Organization for Research and Treatment of Cancer, National Cancer Institute of the United States, National Cancer Institute of Canada. J Natl Cancer Inst 2000, 92(3):205-216.

24. Al-Haddad S, Zhang Z, Leygue E, Snell L, Huang A, Niu Y, Hiller-Hitchcock T, Hole K, Murphy LC, Watson PH: Psoriasin (S100A7) expression and invasive breast cancer. Am J Pathol 1999, 155(6):2057-2066.

25. Dumontet C, Sikic Bl: Mechanisms of action of and resistance to antitubulin agents: microtubule dynamics, drug transport, and cell death. J Clin Oncol 1999, 17(3):1061-1070.

26. Burkhart CA, Kavallaris M, Band Horwitz S: The role of beta-tubulin isotypes in resistance to antimitotic drugs. Biochim Biophys Acta 2001, 1471(2):01-9.

27. Kavallaris M, Kuo DY, Burkhart CA, Regl DL, Norris MD, Haber M, Horwitz SB: Taxol-resistant epithelial ovarian tumors are associated with altered expression of specific beta-tubulin isotypes. J Clin Invest 1997, 100(5):1282-1293.

28. Ranganathan S, Benetatos CA, Colarusso PJ, Dexter DW, Hudes GR: Altered beta-tubulin isotype expression in paclitaxel-resistant human prostate carcinoma cells. Br J Cancer 1998, 77(4):562-566.

29. Liu B, Staren ED, Iwamura T, Appert HE, Howard JM: Mechanisms of taxotere-related drug resistance in pancreatic carcinoma. J Surg Res 2001, 99(2):179-186.

30. Dumontet C, Isaac S, Souquet PJ, Bejui-Thivolet F, Pacheco Y, Peloux N, Frankfurter A, Luduena R, Perol M: Expression of class III beta tubulin in non-small cell lung cancer is correlated with resistance to taxane chemotherapy. Bull Cancer 2005, 92(2):E25-30.

31. Koh Y, Kim TM, Jeon YK, Kwon TK, Hah JH, Lee SH, Kim DW, Wu HG, Rhee CS, Sung MW, et al: Class III beta-tubulin, but not ERCC1, is a strong predictive and prognostic marker in locally advanced head and neck squamous cell carcinoma. Ann Oncol 2009, 20(8):1414-1419.

32. Urano N, Fujiwara Y, Doki Y, Kim SJ, Miyoshi Y, Noguchi S, Miyata H, Takiguchi S, Yasuda T, Yano M, et al: Clinical significance of class III betatubulin expression and its predictive value for resistance to docetaxelbased chemotherapy in gastric cancer. Int J Oncol 2006, 28(2):375-381.

33. Lu M, Gao J, Wang XC, Shen L: Expressions of Thymidylate Synthase, Thymidine Phosphorylase, Class III beta-tubulin, and Excision Repair Cross-complementing Group 1predict Response in Advanced Gastric Cancer Patients Receiving Capecitabine Plus Paclitaxel or Cisplatin. Chin J Cancer Res 2011, 23(4):288-294

34. Kang JH, Lee SI, Lim Do H, Park KW, Oh SY, Kwon HC, Hwang IG, Lee SC, Nam E, Shin DB, et al: Salvage chemotherapy for pretreated gastric cancer: a randomized phase III trial comparing chemotherapy plus best supportive care with best supportive care alone. J Clin Oncol 2012 30(13):1513-1518.

35. Matsubara J, Nishina T, Yamada Y, Moriwaki T, Shimoda T, Kajiwara T, Nakajima TE, Kato K, Hamaguchi T, Shimada $Y$, et al: Impacts of excision repair cross-complementing gene 1 (ERCC1), dihydropyrimidine dehydrogenase, and epidermal growth factor receptor on the outcomes of patients with advanced gastric cancer. Br J Cancer 2008, 98(4):832-839.

36. Liu YP, Ling Y, Qi QF, Zhang YP, Zhang CS, Zhu CT, Wang MH, Pan YD: The effects of ERCC1 expression levels on the chemosensitivity of gastric cancer cells to platinum agents and survival in gastric cancer patients treated with oxaliplatin-based adjuvant chemotherapy. Oncol Lett 2013, 5(3):935-942.

37. Kim JS, Kim MA, Kim TM, Lee SH, Kim DW, Im SA, Kim TY, Kim WH, Yang HK, Heo DS, et al: Biomarker analysis in stage III-IV (M0) gastric cancer patients who received curative surgery followed by adjuvant 5fluorouracil and cisplatin chemotherapy: epidermal growth factor receptor (EGFR) associated with favourable survival. Br J Cancer 2009, 100(5):732-738.

38. Napieralski R, Ott K, Kremer M, Specht K, Vogelsang H, Becker K, Muller M, Lordick F, Fink U, Rudiger Siewert J, et al: Combined GADD45A and thymidine phosphorylase expression levels predict response and survival of neoadjuvant-treated gastric cancer patients. Clin Cancer Res 2005, 11(8):3025-3031.

39. Smith S, Su D, de la Longrais IA R, Schwartz P, Puopolo M, Rutherford TJ, Mor G, Yu H, Katsaros D: ERCC1 genotype and phenotype in epithelial ovarian cancer identify patients likely to benefit from paclitaxel treatment in addition to platinum-based therapy. J Clin Oncol 2007, 25(33):5172-5179.

40. Pasini F, Fraccon AP, DEM G: The role of chemotherapy in metastatic gastric cancer. Anticancer Res 2011, 31(10):3543-3554.

41. Ando T, Hosokawa A, Kajiura S, Itaya Y, Ueda A, Fujinami H, Nishikawa J, Kobayashi T, Horikawa N, Tsukioka Y, et al: Efficacy of weekly paclitaxel in patients with advanced gastric cancer refractory to docetaxel-based chemotherapy. Gastric Cancer 2012, 15(4):427-432.

doi:10.1186/1471-2407-13-431

Cite this article as: Hwang et al: Class III $\beta$-tubulin is a predictive marker for taxane-based chemotherapy in recurrent and metastatic gastric cancer. BMC Cancer 2013 13:431.

\section{Submit your next manuscript to BioMed Central and take full advantage of:}

- Convenient online submission

- Thorough peer review

- No space constraints or color figure charges

- Immediate publication on acceptance

- Inclusion in PubMed, CAS, Scopus and Google Scholar

- Research which is freely available for redistribution 